\title{
A response to industrial maturity and energetic issues: a possible solution based on constructal law
}

\author{
Michele Trancossi
}

Received: 28 February 2014 / Accepted: 14 October 2014 / Published online: 24 January 2015

(C) The Author(s) 2015. This article is published with open access at SpringerLink.com

\begin{abstract}
Purpose Transport vehicle industry is suffering a diffused technological maturity. Energy efficiency is increasing with a certain velocity. But many factors in car development are playing against.

Method A critical literature review about technological maturity symptoms and industrial grade design methods is presented for the current research paper. In particular Multidisciplinary Design Optimization and Modular System Design has been considered. A technical and scientific discussion, is performed focusing on the technological effect they are generating.

Results A possible answer comes from the MAAT 7th framework Program which defined a novel design method initially conceived for airships. It has been defined CDE, Constructal Design for Efficiency. It is specifically based on Constructal law and second Principle of Thermodynamics and aims to produce an original methodological synthesis of Modular Design principles and Multidisciplinary Optimization harmonizing them by thermodynamic principles. The result of this process allows tuning CDE on the road through an effective generalization of the preliminary CDE concept. The schematization of the necessary design process of a vehicle has presented and discussed.
\end{abstract}

Keywords Constructal · Design · Vehicles · Optimization
Abbreviations
CDE Constructal design for efficiency
MDO Multidisciplinary design optimization
A Frontal area $\left[\mathrm{m}^{2}\right]$
$\mathrm{C}_{\mathrm{D}} \quad$ Drag coefficient [-]

M. Trancossi $(\bowtie)$

Universita di Modena e Reggio Emilia, Di.S.M.I., Via Amendola,

2-42100 Reggio Emilia, Italy

e-mail: michele.trancossi@unimore.it

$\begin{array}{ll}\mathrm{c} & \text { Friction coefficient }[-] \\ \mathrm{Ex} & \text { Dissipated energy }[\mathrm{kJ}] \\ \mathrm{g} & \text { Acceleration of gravity }\left[\mathrm{m} / \mathrm{s}^{2}\right] \\ \mathrm{m} & \text { Mass }[\mathrm{kg}] \\ \mathrm{m}_{\mathrm{p}} & \text { Mass of payload }[\mathrm{kg}] \\ \mathrm{m}_{\mathrm{tot}} & \text { Total mass }[\mathrm{kg}] \\ \mathrm{t} & \text { Time }[\mathrm{s}] \\ \mathrm{v} & \text { Velocity }[\mathrm{m} / \mathrm{s}] \\ \mathrm{v}_{\mathrm{av}} & \text { Average velocity }[\mathrm{m} / \mathrm{s}] \\ \mathrm{v}_{\mathrm{max}} & \text { Maximum velocity }[\mathrm{m} / \mathrm{s}]\end{array}$

\section{Introduction}

A transportation vehicle is not just a physical product of technology. It assumes economic, environmental, social, cultural, and political dimensions $[1,2]$. The transport vehicle industry refers to a technological system, which is larger than simple manufacturing, use, recycling, and disposal. It requires infrastructure-related technologies (road, highways, bridges, tunnels, railways, stations, airports, harbours, etc.) and energy production, conversion and transport systems. Infrastructure and energy have been the most influential economic sectors of the last decades of 20 th century.

The industry of transport vehicles is a 'technological regime' as defined by Weber. [3]. A 'technological regime' is a key strategic domain of any developed territory. It involves different elements: scientific knowledge, engineering practices, technologies, industrial processes, product value, human skills, human experience, procedures and infrastructures.

In these key areas, inadequate or short-sighted choices can produce large social problems.

Transport vehicle industry is now facing a diffused maturity phase, even if distances travelled for person are increasing. Today vehicles present an improved styling, an increased comfort and safety and a very large range of accessories. 
A more technically skilled observation leads to a radically different perception. A fundamental question could arise: "What has changed with respect to a vehicle produced twenty years ago?" Any answer to this question will respond evidencing innovations which are perceived as minor by common users. On the other side, if this analysis focuses on energetic point of view, it shows large contradictions.

For example, if we compare today cars with the ones of twenty years ago, they seem more functional and have richer and more functional equipments. These results have been produced by a continuous increase of weight, which is absolutely a negative effect both in terms of consumption and dynamic behavior. As we will see inside the paper, vehicle industry has produced some minor improvements and minor increases in terms of performances. Otherwise, energetic, aerodynamic and environmental and end-of-life issues are still far from an effective solution.

The main reason of the limited capability of facing adequately the main challenges of our society is this technological paradigm. It is orienting design and manufacture and limiting available alternatives. The results are evident if we look at the automotive sector. Differences among competitors are reducing. Vehicles are becoming nearly identical in terms of both powertrain and performances. It affects directly the market, which is based only on price, aesthetic and service considerations. It produces negative effects, such as lack of innovation, competition on prices and technological maturity.

These considerations forces to a preliminary analysis of the risks connected to technological maturity and of the causes of today scenario of industrial maturity. It analyzes the influence of today most used design methods which have large responsibility on this situation. It traces then the guidelines through a novel design method, which has specifically defined for encouraging innovation. It is based on Constructal law principles of thermodynamics and aims to produce optimized design on an energetic point of view.

It aims to open new roads through an effective solution to overcome industrial maturity and today economical crisis. This design method has been defined in MAAT EU 7th Framework Program project. It has specifically defined to allow design of energy self-sufficient airships. This paper aims to produce a possible generalization of this method. It aims to stimulate the effective definition of an industrial design method based on Constructal law.

\section{Materials and methods}

\subsection{Cyclic theory and maturity effects}

Nikolai Kondratieff [4-6] noted that many economic indices have a cyclic regularity. He argued that some indices increase during the periods of economic expansion and other increases during the periods of decline. He remarked that it is possible to individuate economic cycles of about 50 years along recent human history.

Kondratieff identified four distinct phases of the economic cycles (Fig. 1). They are:

- Spring phase: high levels of production, increasing wellness, rising inflation;

- Summer: economic 'peak' and high inflation followed by societal doubts;

- Autumn: reduction of inflation leads to a credit boom, which creates a false plateau of prosperity that ends in a speculative bubble;

- Winter: excess capacity worked off by massive debt rejection, commodity deflation and economic depression.

Schumpeter focused on social and economical issues related to cyclic models [7-9]. He characterized the different economic phases defined by Kondratieff. Schumpeter observed that the main propulsion of economy is the entrepreneurial innovation. Heroic entrepreneurs generate any longterm economic development. They are pioneers, who have the capability of combining scientific state of the art, creativity and original ideas to create new combinations. This activity leads to a new cluster of basic innovations, which can propel novel possibility of industrial development in the long term.

On an industrial point of view, the winter phase presents clear symptoms. Prices and profits decreases. Companies attempt to increase the market basis in less developed countries. Innovation of traditional technologies seems difficult and very expansive for the results. Mensch [10] has described this situation. It can be overcome by fundamental innovations that generate new market opportunities for the future. Mensch argued that clusters of innovation could arise to success during depressive economic cycles. During this negative period, companies accept the risk of investing in radical new concepts and technologies.

The cyclic theory clearly states that economic development is driven by technological innovations as stated by Van Duijn [11].

Technological maturity appears by different concurring effects. A product configuration is near the maximum performance levels it can reach, innovation becomes very expensive

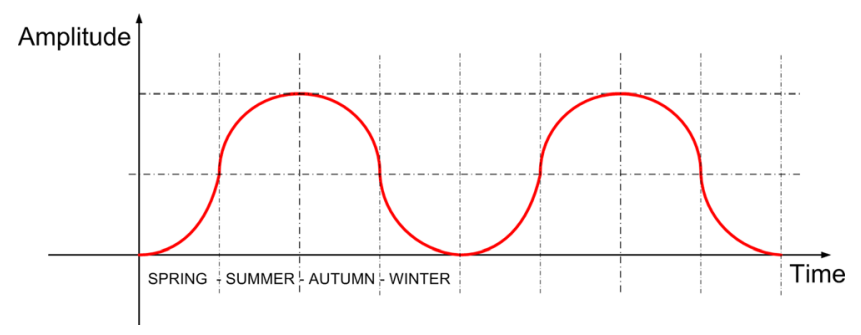

Fig. 1 Seasons of the Kondratieff cycles 
and market is no more leaded by innovation but by simple substitution of existing products.

\subsection{Industrial maturity symptoms in today industrial panorama}

Typical symptoms of maturity are a diffused standardization of industrial products. The competition is based on prices, on marketing, and not on technical contents. Typical effects are an economic slowdown in traditional rich countries, the shift of industrial production to emerging countries with lower costs. Further effects are increasing of unemployment and concentration of richness.

The market of transport vehicles, of any nature - except electric cars and unmanned vehicles - is going through a typical winter condition. Producers are concentrating. Production is moving to emerging counties to expand the market [12]. Increasing unemployment affects the less economically structured rich countries. These symptoms identifies the depressive moments of long-term technological waves. They lead to a reduction of wellness, with economic, social and political instability.

Technological analysis confirms that transport vehicle industry has obvious symptoms of maturity. They are evident in the ground vehicle industry and affects also manufacturing of subcomponents. Most diffused aeronautic concepts (defined during World War II) have reached maturity. Air vehicles with increased performances and cargo capacity, reduced consumption of energy and lowered environmental impacts could be possible by further evolution of traditional architectures. Expected gains appear reduced if compared with associated costs using today aircraft architectures [13].

Maturity problems are shown by technical problems and costs of long-range airliner projects such as Airbus A380 and Boeing 787. Cited problems relates to the structure of wings and batteries on the first units delivered [14]. Less sophisticated regional transport airplanes still ensures higher margins of evolution because they still present some technological delays if compared to the long-range airliners. The example of A320Neo and B737Max shows that aircrafts for regional transport could be more profitable. They also envisage larger margins of growth despite the increase of global competitors [14].

The automotive market is declining for vehicles produced and sold in Europe and US [15]. One reason is the actual economic and social crisis. Another one is the high-level of maturity [16] of ground vehicles. Today they seem marginally better than the ones produced few decades ago. More sophisticate design, minor increase of performances, of safety equipments [17], and minor reduction of fuel consumption [18], are not enough for an expansive market driven by innovation [19]. Consequently, the market is characterized by simple substitution in most advanced countries. Lowering the cost of production becomes the main element of the competition [20].
Younger electronic and computer industry is also suffering symptoms of maturity, even if market is still increasing because the fall of prices for calculation capacity [21].

The fall of the sales of transport vehicles and slowing prices of electronics are fundamental parts of the crisis that our society is facing. This crisis is not only financial, but also especially industrial [22].

\subsection{Today design methods}

Today industrial maturity is increased by the design methods used today at industrial level. The need of increasing products reliability and reducing industrial costs has led to modular product platforms [23]. This modular industrial model produced a redefinition of design methods. In particular, those design methods have hastened the maturity. They are:

1. Multidisciplinary Design Optimization (MDO) preliminarily defined by Avriel [24] in 1973,

2. Modular System Design (MSD) introduced by Erickson [25], and Clark and Baldwin [26, 27].

These methods can be analyzed in detail, focusing on their effects on the present scenario.

\subsubsection{Multidisciplinary design optimization}

Papalambros [28] defines Multidisciplinary Design based on the terms that form its name. A system is a physical or virtual object. It presents specific behaviours or performs specific activities by interactions of constitutive parts. Multidisciplinary means that design needs several contributions by different disciplinary areas. They can be expressed by governing equations from various physical, economic, social fields. Design aims creating and planning industrial products or processes by specific goals. It aims reaching valuable effects at industrial or financial level. The design problem can be defined by objective functions. These functions are vectors comprising any issue related to product design. They include behaviour, features, performances, costs, use of resources, economic parameters, risks, etc. Design consists in an optimization process that aims to minimize or maximize the objective functions.

The Multidisciplinary Design Optimization Method (MDO) has been defined by different authors, such as Steuer [29], Cramer [30], Raymer [31], Alexandrov [32] and Vanderplaats [33]. They state clearly that problem formulation is the most difficult part of the process. It consists in selecting design variables, constraints, objectives, and models by the involved disciplines. A further consideration regards strength 


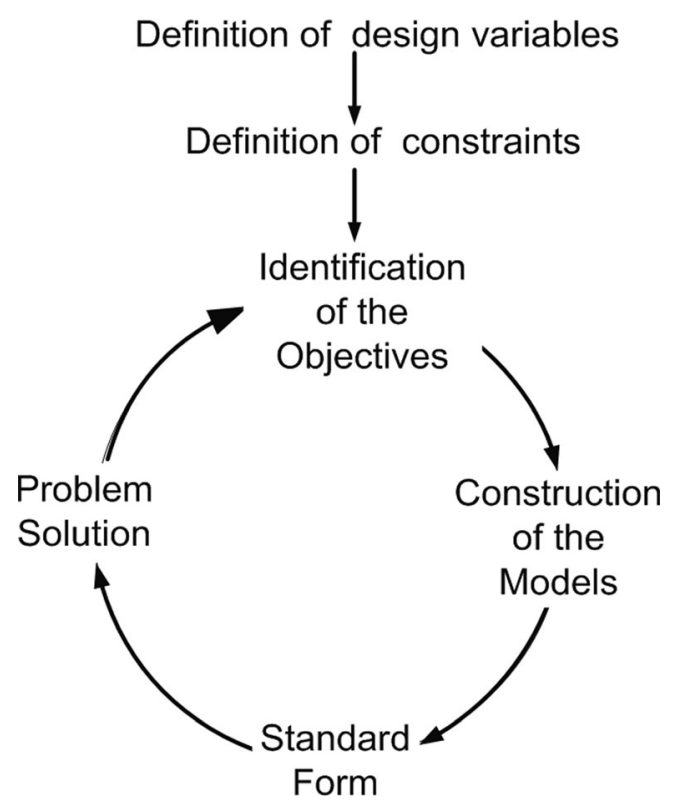

Fig. 2 Phases of MDO design and optimization method

and extent of the interdisciplinary coupling in the problem. The method considers different steps (Fig. 2):

1. Definition of design variables

Design variables is any element, which is controllable by the designer. A set of values forms the boundary conditions of design problem (i.e. properties of the materials, any independent measure, functions and properties, etc.). Design variables can be continuous in a predefined interval, discrete or Boolean, depending on their specific nature. They are often limited inside a predefined range. The bounds of this range can be assumed as numerical constraints or separately.

2. Definition of constraints

A constraint is a condition that must be satisfied to produce an effective product feasibility or industrial manufacturability. For example, in case of aircraft design, it is necessary that lift generated by wings is equal to the weight. The design constraints have different natures: physical laws, resources, user needs, bounds of validity, etc. Constraints can be explicit terms of the algorithm or implicitly incorporated into the objective by Lagrange multipliers.

\section{Statement of objectives}

The objectives can relate to any variable of the problem. They can be expressed in different terms, such as minimization, maximization or approaching a predefined numerical value. They define feasible targets, which ensure an optimum condition. Examples are minimizing cost and weight, reaching an energy consumption level rather than a performance level, etc. Many solution methods work only with single objectives. Three solutions methods are allowed:

- single objective analysis,

- synthetic objective analysis: it is a single objective analysis using a synthetic objective which is the weighted sum or average of different elemental objectives;

- multi-objective optimization, it is an optimization on several objectives, such as calculating a Pareto front.

- Construction of the models

The specific constraints and variables of the design relates to the objectives thought specific equations by the variables of the problem. In this way, specific models are defined. They relate constraints and objectives to the design variables, by equations depending on the involved disciplines in the project. Those models allow different solutions such as regression analysis of the prices, theoretical models, drawn from the governing laws of physics, such as structural and fluiddynamic relations. It is also possible to adopt simplified relations especially in the preliminary phases of design. The multidisciplinary nature of most design problems can generate complicated models with a large set of variables and equations involved. The number of equations and their complexity affects both calculation times and multiple interactions between different terms. I.e., the aerodynamic loads on a wing affect its structural deformation. The structural deformation affects shapes and dimensions of the wing and the aerodynamic loads. In this case, it is necessary to run several steps of aerodynamic and structural analyses. They allow getting a systematic solution with sufficient precision (convergence of the problem).

\subsection{Standard form solution}

Once design variables, constraints, objectives have defined, and the relationships between them can be expressed. The problem can be then expressed for each variable in the following elemental form: find $x$ that minimizes (or maximizes) $J(x)$ subject to a set of relations such as

$g(x-c) \geqq 0, h(x-d)=(0)$ and $x_{\text {min }}<x<x_{\max }$

where $\mathrm{J}$ is an objective, $x$ is a vector of design variables, $g$ is a vector of inequality constraints, $\mathrm{h}$ is another vector of equality constraints, $c$ and $d$ are constants and $x_{\min }$ and $x_{\max }$ are vectors, which constitutes lower and upper bounds, which applies on the design variables. By reducing the problem to the above form and solving it carefully, it can be obtained a possible solution or a range of possible solutions. 


\subsection{Problem solution}

It is possible to find a solution for any specific problem by appropriate mathematical or numerical techniques. Different algorithms allow solving the design problem: genetic algorithms, gradient-based algorithms, population-based algorithms, but also in simplified problems linear methods.

\subsubsection{Modular system design}

The Modular System Design (MSD) is a result of product platform architecture, which has been made up by interchangeable subsystems [34-36]. It has massively adopted in many industrial fields, such as building, automotive, electronic and appliance industries. It allows producing a large set of industrial advantages by reducing design efforts, time-tomarket times and cost of the parts, which are strongly standardized.

MSD needs a collaborative structure, which allows organizing specialist from various disciplines into multidisciplinary teams. It reduces the coordination costs but has the opportunity of creating a modular team-based organization.

A key benefit of modular design is lowering levels of the design hierarchy. It allows creating an evolving system that can develop on time. The main advantage of the MSD is a certain degree of tolerance and uncertainty in the early phase. However, once settled, it gets rigid and long lasting.

There are certain generic design actions one can apply to a modular system. Holland [37] have defined the actions of a modular system as "operators". Baldwin and Clark [38] have identified different modular operators and analyzed their potential economic value. They have explained that any system can splits in modules and that it is always possible to design a novel module, which can substitute the original one.

Figure 3 shows the effect of modular design on a complex system. A modular system is not a full interdependent system. It is a matrix of interoperable modules governed by design rules. This design method allows enlarging the number of design options and the possibilities of different ways of evolution. In this way, a system can move decisions from a central point of control to several points of control, one for individual module.

The main innovation of the modular design system relates to its possibility of evolving in different ways because of different directions of evolution of the various modules. It also presents a fundamental intrinsic limit. The performances of the worst module condition the ones of the system. I.e., overall performances of personal computers are determined by the subsystem with lowest ones.

On the other side, this design approach has the effect of creating a fundamental barrier to market entry of new competitors because of the high costs for developing a complex engineering system. However, it reduces the costs of
Full System

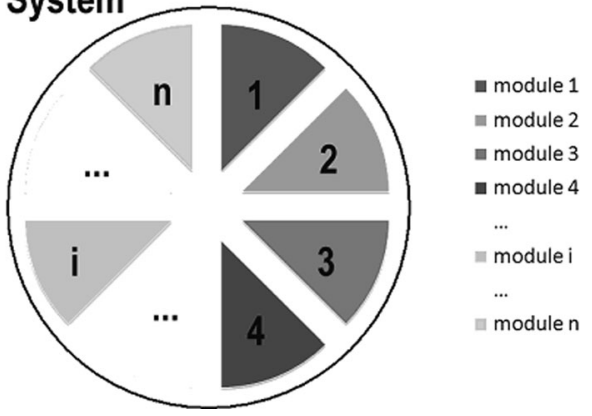

Fig. 3 Sample of modularization of a system

developing individual modules. It facilitates then the industrial concentration at system level, but creates competition at module level.

The application of MSD is paradigmatic into automotive industries, where it produces an extreme platform concept. A platform is a set of common design, engineering, and production standards [39]. Most industrial components shares over a number of outwardly distinct models and even types of automobiles from different industrial groups and brands.

This model has massively adopted to lower the costs associated to product development and to product manufacturing. It also allows basing several products on a much-reduced number of platforms [40]. The most important element consequence of platform sharing is that different products and different brands share the same components [41] with the main purpose of platform sharing to reduce the cost and have a more efficient product development process. The companies have fundamental gains in terms of scale economies, because of sharing most of the components, but they limit the differentiation of the products, losing their tangible uniqueness.

The first automotive modules defined during the $70 \mathrm{~s}$ and 80 s include mainly underbody (front floor, underfloor, engine compartment and frame) and suspensions (with axles). Actually, the platform concept has been extended to a larger set of components. It defines a set of common choices, which serves as a foundation for the chassis and other structural and mechanical components; front and rear axles and wheelbase; steering mechanism and type of power steering, type of front and rear suspensions; placement and choice of engine and other power-train components.

Platform sharing together with advanced manufacturing technology produces an effective reduction of product development and changeover times. The automotive firms define the platform as vehicle architecture, introducing also a further limit related to the placing of physical components.

The use of a platform strategy provides several benefits at industrial level [42]:

- increased flexibility of plants: the production of a model can be easily moved from one plant to another due to strong standardization; 
- cost reduction: it is achieved through using standardized components and resources on a global scale,

- $\quad$ increased use of plants: higher productivity potential is due to the reduction in the number of differences between the different models;

- reduction of the number of platforms: it is an effective engine of the globalization of similar productions on worldwide basis;

The automobile platform strategy has limited the differentiation of the products on a worldwide basis minimizing the expenses of product development and the possibility of the innovation process. In the first times, it has generated and increased quality enhancement and reduced costs of production. Instead, on a 30 years basis it has produced very conservative choices and a situation of diffused technological maturity [43]. It is responsible of the lack of distinctiveness of the products. It has also minimized the technical differentiations between products, which becomes limited to marginal components and aesthetic element.

\subsection{Industrial effects of today design methods}

The success of MSD and MDO has been the cause of a diffused technological maturity situation of most industrial sectors. It has produced a radical concentration of possible system architectures in few ones. It has limited the product design possibilities inside a limited number of accepted configurations. The innovation is concentrated on singular modules. Usually, it is not supported by a precise strategy that allows maximizing the effects of the innovation. Performances of modularized and standardized products are not conditioned by the most advanced components but by the worst one [44] on the function path. This is evident looking at computer performances and PV plants performances, which are characterized by the worst component.

Another effect of the platform concept relates to the very conservative design results because of two concomitant reasons: the innovation inside a platform is at single component level; the development of a new platform is conditioned by the presence of many standardized components. It produces a well-defined architecture, with limited spaces for innovation. It is then evident that the product platform logic limits the choice in terms of possible architectures and lead to an excess of standardization and to a consequently increases the levels of technological maturity.

The combined application of Multidisciplinary Design Optimization, Modular Design and Product Platform model produces important effects and is causing (on the long term) a large set of negative aspects, which can be identified:

1. limited possibility of access to the market: the high costs of technologies at full product scale size and intrinsic concentration of the market players is producing a large reduction in terms of unitary prices and margins;

2. limited margins of innovations: innovation is performed inside a well defined system platform, which is strongly standardized and limited at component and subcomponent level;

3. limited performance and margins of improvement: the improvement at component level can produce some benefits at system level but they are always much reduced if compared to the ones that could be possible with a global product redesign or at least a complete redesign of the components inside a functional chain;

4. reduction of competences at social level: the modular design and production causes a significant reduction of specific professional and technical competences at social level because of the consequent reduction in terms of occupation.

\subsection{Effects of today design methods}

A sample of the distorted effects that MSD and platform concept produce is clear by examining the vehicle development during the last decades. The critical path of a vehicle is the energetic one because of its impacts in terms of energetic and environmental effects. Figure 4 presents a simplified schema of the power-train of a traditional ICE (Internal Combustion Engine) vehicle. This schema shows clearly the energy losses by evidencing their causes [43].

This analysis produces specific benefit, which could be possible by an effective optimization of internal combustion vehicles, which are the most critical in terms of both energy efficiency and emissions.

It considers the full vehicle taking into consideration the energy losses for moving the vehicle. Losses depend on the regime in which the vehicle operates (urban, highway or composite). The valuation of power needs can be performed by Eq. (13)

$E x_{\text {vehicle }}=m_{t o t}\left(c g v_{a v} t+\frac{1}{2} v_{\max }^{2}\right)+\frac{1}{2} C_{D} A P_{a i r} v_{a v}^{3} t$

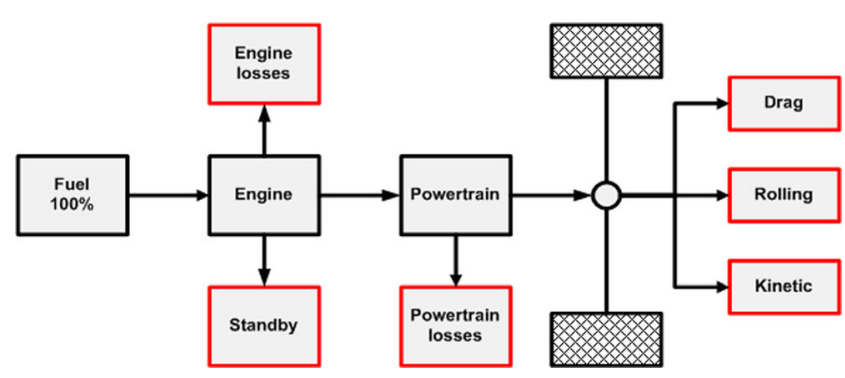

Fig. 4 Losses in a ground vehicle 
Equation 1 can be reassembled in three key terms:

$$
E x_{\text {vehicle }}=m_{\text {tot }} \cdot \operatorname{cg} v_{a t} t+m_{\text {tot }} \frac{1}{2} v_{\max }^{2}+\frac{1}{2} C_{D} A P_{a i r} v_{a v}^{3} t
$$

where:

- $\quad E x_{\text {friction }}=m_{\text {tot }} . c g v_{a t} t$ is the dissipative term due to friction;

- $E x_{\text {kin }}=m_{\text {tot }} \frac{1}{2} v_{\max }^{2}$ is the dissipative kinetic term due to max speed reaching

- $E x_{\text {drag }}=\frac{1}{2} C_{D} A \rho_{\text {air }} v_{a v}^{3} t$ is the dissipative terms due to aerodynamic drag

It can be also possible to write the energy losses due to engine and to power train:

$E x_{\text {vehicle }}=E x_{\text {fuel }}-L_{\text {engine }}-L_{\text {stanby }}-L_{\text {Powertrain }}$

According to equations (1 and 2 ) it is possible a more sophisticated analysis about performances during operations of different vehicles in service conditions. In particular, cars, busses and trucks have been considered.

Preliminary calculations have performed against Sovran and Bohn [44]. The results have shown in Table 1. They show the full energetic value of the fuel and results appear perfectly in line with Sovran and Bohn ones. Calculations have performed for an average car, a truck and a bus. A midsize car (1.3 ton) a heavy truck (40 ton full payload) and a bus (16 ton) have considered as preliminary references.

The dissipative terms can be rewritten in terms of energy dissipations cause to the vehicle and by the payload:

$E x_{\text {vehicle }}=m_{v}\left(c g v_{a v} t+\frac{1}{2} v_{\max }^{2}\right)+\frac{1}{2} C_{D} A \rho_{a i r} v_{a v}^{3} t$ is the component due to vehicle even at zero payload

$E x_{\text {payload }}=m_{p}\left(c g v_{a v} t+\frac{1}{2} v_{\max }^{2}\right)$

is the component due to payload.

These equations show clearly that the vehicle, even if divided into subsystems and internal functional blocks are a unitary element. It is also evident that two factors present a very large influence on energy consumption at vehicle level. They are the masses $\left(m_{v}\right.$ and $\left.m_{p}\right)$ and the drag coefficient CD.

It is evident that the reduction of mass is a positive aspect together with the reduction of CD and frontal section. MSD has produced a large increment of mass, instead. This increment is clearly shown in Fig. 5 that evidences the evolution in terms of weight of some typical European small cars. The mass increase causes has reduced the potential reduction of energy consumption that could be achieved by the improvement at engine and power-train level. It has been a direct consequence of MSD design method, which has not produced any optimization at vehicle level.

\subsection{The necessity of increasing the rate of innovation}

The actual level of technology maturity, which has favoured by coupled applications of MDO and MSD, requires new answers. A future economic expansive phase requires an effective transition from a market of simple substitution to a market driven by innovation. The actual market crisis makes it more necessary in the transport sector, especially in the automotive sector to force customers to a massive substitution of circulating vehicles.

Looking at transport vehicles related industry, the increasing consciousness of the future energetic and environmental issues is evident from European Commission documents

Table 1 Reference values of energy consumption (\%) in city, highway and composite regimes

\begin{tabular}{|c|c|c|c|c|c|c|c|c|c|c|}
\hline & & \multicolumn{3}{|l|}{ Car } & \multicolumn{3}{|l|}{ Truck } & \multicolumn{3}{|l|}{ Bus } \\
\hline & & $\begin{array}{l}\text { City } \\
\%\end{array}$ & $\begin{array}{l}\mathrm{H} \text { way } \\
\%\end{array}$ & $\begin{array}{l}\text { Comp } \\
\%\end{array}$ & $\begin{array}{l}\text { City } \\
\%\end{array}$ & $\begin{array}{l}\text { H way } \\
\%\end{array}$ & $\begin{array}{l}\text { Comp } \\
\%\end{array}$ & $\begin{array}{l}\text { City } \\
\%\end{array}$ & $\begin{array}{l}\mathrm{H} \text { way } \\
\%\end{array}$ & $\begin{array}{l}\text { Comp } \\
\%\end{array}$ \\
\hline \multirow[t]{4}{*}{ Engine } & Fuel tank & 100.0 & 100.0 & 100.0 & 100.0 & 100.0 & 100.0 & 100.0 & 100.0 & 100.0 \\
\hline & Engine & 74.0 & 70.0 & 72.0 & 65.0 & 60.0 & 62.5 & 62.0 & 60.0 & 61.0 \\
\hline & Standby & 6.0 & 0.5 & 3.3 & 5.0 & 1.0 & 3.0 & 8.0 & 1.5 & 4.8 \\
\hline & Output & 20.0 & 30.5 & 25.3 & 30.0 & 39.0 & 34.5 & 30.0 & 38.5 & 34.3 \\
\hline \multirow[t]{2}{*}{ Power train } & Driveline & 4.0 & 5.0 & 4.5 & 8.0 & 5.0 & 6.5 & 8.0 & 5.0 & 6.5 \\
\hline & Output & 16.0 & 25.5 & 20.8 & 22.0 & 34.0 & 28.0 & 22.0 & 33.5 & 27.8 \\
\hline \multirow[t]{3}{*}{ Operations } & Rolling & 4.4 & 9.0 & 6.3 & 4.4 & 11.1 & 7.7 & 4.4 & 12.1 & 8.3 \\
\hline & Drag & 2.9 & 12.9 & 6.2 & 4.4 & 18.7 & 11.6 & 3.6 & 18.6 & 11.1 \\
\hline & Kinetic & 8.7 & 3.7 & 8.2 & 11.0 & 2.6 & 6.8 & 14.0 & 2.8 & 8.4 \\
\hline
\end{tabular}




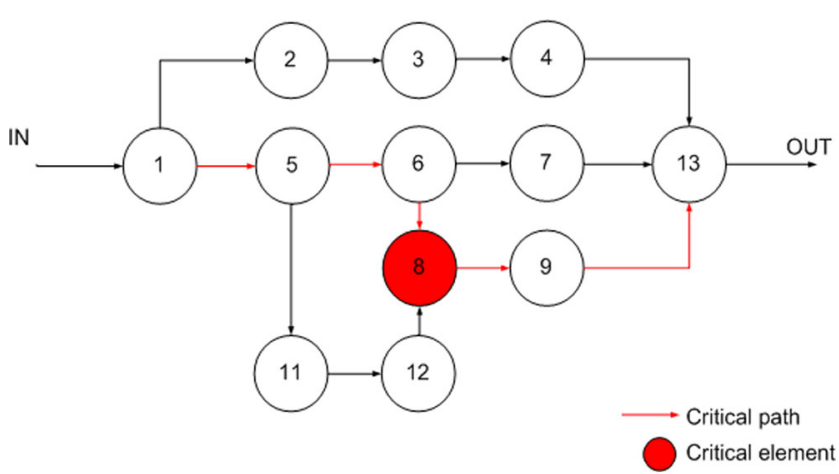

Fig. 5 Mass trend of three great diffusion vehicles

[45-49]. Actual directions of development are producing some results but they are much reduced if compared to the effective and specific needs.

It is necessary to produce future innovations even radical for an effective increase of energy efficiency and environmental sustainability. Similar considerations apply to automotive sector and more dramatically to the appliances sector. Performances and lifetime of the system are characterized by worst components also because of high costs of spare parts.

Other important problems caused by design methods involve aerial transport. They concern some important operative issues:

- increasing capacity and lowering congestion of larger airports,

- integration with other transport modes,

- greening issues such as reduction of fuel consumption and emissions.

It is necessary to define novel design methods for innovation, which can provide an effective answer to energetic, environmental and operative issues.

An effective solution to these problems require novel design approaches that accepts product modularization and platform design methods but allows an increased level of optimization and innovation for the future. It requires a cultural revolution.

The most important needs for the future relate necessarily to energy efficiency lower usage of resources and consequent reduction of emissions. Modular design and product platform concept have driven by a leadership of financial function over creative, technical and scientific. It is now necessary to recreate an effective equilibrium of these functions and to produce the necessary levels of innovation. This exigency could be synthesized in a new design method, which must necessarily include the positive aspects of modular design. It needs also to overcome the rigidity by ensuring intrinsically an adequate level of innovation. Such a model is necessary, to have the possibility of producing an effective rebirth of market possibilities and industrial productivity. This rebirth is the necessary condition for a long-term economical rebirth for the future.

\subsection{Constructal theory: a possible answer}

\subsubsection{Constructal law}

A possible answer to the future needs comes from the controversial Constructal theory theorized by Adrian Bejan [50-52]. It allows defining a design method based on the physic laws of a complex system. It takes origin from the constructal law, which is a generalization of first principle and second principle of thermodynamics. Constructal theory assumes that the configuration of any system is subject to a basic principle, named Constructal law [53].

"For a finite-size flow system to persist in time to survive its configuration must evolve in such a way that it provides an easier access to the currents that flow through it".

The Constructal law has been defined in 1996 as a summary of all design generation and evolution phenomena in nature. It also aims to describe the evolution steps in natural process, and attribute the design processes to the dominion of physics [54]. Designs have the universal tendency to evolve in a certain direction in time [55].

It aims describing the natural evolution of natural systems and the design that they assume in the time. The evolution of nature tends to facilitate the flow and any natural structure evolves in this direction.

The constructal law provides a precise answer in the domain of natural laws: it explains the natural tendency of nature to generate designs that facilitates facilitate flow [56].

\subsubsection{Constructal law and natural evolution}

The constructal law describes the reasons of some typical natural laws such as tree-like structure in all designs that allows a current to move from a point to an area and vice versa from an area to a point (river basins, flashes, circulatory and nervous systems). Although treelike structures are a very common design in nature, they are only one manifestation of the constructal law.

The constructal law explains also the time direction of many natural evolutionary design phenomena, acquiring over time configurations that improves their performances. It states that design generation and evolution are macroscopic phenomena of physics that arise naturally to provide better and better flow access to the currents that run through them.

In particular, natural phenomena evolve without eliminating the defects or imperfections, but distribute them minimizing their effects. For example, if a river has to pass a bottleneck it erodes the bottleneck to enlarge it and allow a better flowing. The resulting shape is not the best one, but the one that can produce a better distribution of the imperfections. 
This process generates the geometry, shape and structure of natural systems [57, 58].

Some design activities has realized by the constructal law. It has produced interesting results in the optimization of electronic equipments, fluid dynamic and thermodynamic systems and tree networks for transport of people, goods, and information.

\subsubsection{Design by constructal law}

The constructal law can apply with interesting results in engineering simple systems. It applies with a typical bottomup optimization schema:

- a system can be divided into subsystems (elemental parts) using tree models;

- it is necessary to optimize the system starting from the most disadvantaged elemental parts.

This method has produced very good results related to the design of a system with relative low complexity and low interdisciplinary connections.

For example, a heat exchanger or a network system can be optimized by the present formulation of the constructal method.

Figure 4 explains the constructal design model assuming the flow of any measurable physical quantity. It evidences the critical path, which oppose the maximal resistance to the flow. A particular path can be analyzed. It is possible to optimize the critical element by producing a balanced configuration. It is the one that oppose the minimal resistance. Starting from it the whole system can be dimensioned to reduce the resistance to the flow and consequently the full critical path can be designed.

This method easily applies to simple systems based on the flow of a singular quantity. It presents more difficulties when it is applied to the design of a more complex system that depends on many physical quantities (i.e. vehicles, industrial production plants, etc.).

In this case, it can optimize any subsystem and path but without a general system, preliminary analysis it is not sure that the result of the design process is really the optimal one for the objectives. Applying it rigidly it can be produced an effective optimization of the components of a system. It is not sure that the resulting system is the optimal one, without an optimization at system level.

The present formulation of the Constructal Design Method responds to the goal of maintaining the positive aspects of MSD and MDO. However, it improves MSD substantially because it does not maintain the same rigidity. This formulation is still limited because it produces a bottom-up design approach and does not require a preventive top-down optimization at full system level. It maintains then one of the traditional limits of all the bottom-up design cycles, which risk working on predefined arbitrary system layouts.

\subsection{Constructal design for efficiency method}

It is clear that constructal theory is not an actual design method for complex engineering method. It needs further activity to become a suitable engineering design method. The above analysis of design methods shows that only a superior level of optimization allows optimizing the configurations of a physical system. It is then necessary a preliminary design with a top-down approach. According to constructal law, it is possible to optimize a full system by considering it a subsystem of the external environment. The constructal optimization can then consider the interaction of the system with the external environment.

Trancossi et al. [59, 60], Dumas et al. [61] have analysed the complex problem related to the design of specific airships for unconventional mission profiles and energy efficiency by applying the constructal law. They have defined a multilevel constructal law application implementing previous constructal design samples. They have defined a possible implementation of the constructal design method based on multiple cycles. They have introduced a preliminary top-down optimization of the full system and a following bottom up optimization of the internal components. The derived design and optimization method has been named Constructal Design for Efficiency (CDE) to signify its origin from the Constructal theory. They have developed the initial intuition in a systemic way focusing on energy efficient airship design and on thermodynamic and industrial optimization of an entropic wall for a more efficient building insulation [62]. Trancossi et al. [62] have also produced a new Coanda effect nozzle expressly designed for fast transient behaviour.

In particular, an embryonic definition of this design method [59-61] allowed producing an effective energetic optimization of a Zeppelin NT class airship reaching the goal of energy self-sufficiency.

This formulation reassumes in the following steps:

1. a preliminary top-down design process to ensure that the full system has an effectively acceptable configurations for the specified goals (contour conditions for constructal optimization could be stated ensuring an effective optimization at full-system level);

2. the constructal optimization of the elemental components to maximize the system performances;

3. a comparison between different configurations, if they exists, identifying the better possible solution for the predefined goals.

The preliminary top-down optimization process produces an effective constructal optimization of the full system, considered as a subsystem of the environment in which it operates. This approach means that the improvement proposed to the Constructal method is not an addiction or an amendment. It is only an application inside a larger domain. 
This addition allows extending the Constructal principle to the optimization of the design of both the full system and its subcomponents. The dual stage process also ensures a higher confidence about the possibility of reaching an effective optimal solution for the design goals.

In this way, the constructal law and first principle of thermodynamics become the fundament of an effective design methodology, which could allow overcoming the actual maturity crisis of most industrial sectors. The double design process allows overcoming any limitation about the configurations and allowing the definition of the necessary breakthrough innovations, which could revitalize the market in sectors, which appears mostly limited to the substitution.

The definition of an effective design method could allow producing an effective innovation of the products and create a novel demand. It is a potential instrument for proposing to the potential customers effective step advancements, and product much better than the existing ones. In this way, it could be possible to restore the primacy of engineering, physics and mathematics on design activity.

\subsection{A better formulation of $\mathrm{CDE}$}

The previous definition and samples relates to an initial formulation of CDE method, but it requires a more effective definition that allows an effective application at industrial level.

It needs a more effective definition, which allows an effective application at industrial level. This definition aims to integrate somehow the positive aspects of modular design method and the consequent platform concept.

In example a ground vehicle according to $\mathrm{CDE}$ can be described by different modules connected each other. A tree schematization has presented in Fig. 6. A block diagram organized in terms of function can describe the interactions between different elements.

A more evolved schematic representation has produced in Fig. 7. it shows the fluxes of different measurable physical quantities through the different functional blocks. It also shows how the fluxes of the different physical magnitudes and their operative limits.

This schema allows defining some common sense rules. They relates to the necessary simplicity of the structure. It is preferable an elemental structure that limits interactions between the flows of different magnitudes. The independence between flows of different magnitudes allows increase the possibility of substituting single subsystem or entire subtrees with ease. It is then useful to minimize the interaction between the different subsystems. In this way the substitution of an existing module with any other, which can ensure better performances, is simple. It means that product can be updated with ease with minor setup in the manufacturing process.

The second fundamental rule regards the necessity of minimizing the complexity anytime it is possible. Simplicity allows optimizing sub-system design by defining the objectives and consequently the possible improvements in the critical paths that require their satisfaction. This mechanism allows identifying the necessary criteria of discrimination between possible improvements. It is then necessary to conceive a fully optimized vehicle at conceptual level. It allows conceiving an ideal vehicle and together the optimization goals for different sub-trees and subsystems. This ideal vehicle constitutes the best possible vehicle, which could be produced.

The third relates to the necessity of limiting the technological constraints. The technological evolution, which must be free from any specific design, is independent from product platforms. Substantial updates are encouraged respect the actual technology readiness level. The product platform must necessarily consider how to implement an effective level of optimization. Then, it can ensure an easier integration of new modules, but also an increased possibility of applying also substantial modifications to the platform.

It can be then produced an higher level of optimization and can has the ambition to have a longer operative life than the ones defined by the tradition Modular Design method.

These reflections help the formulation of an effective definition of CDE method:

"A complex system can meet optimal performances if it has been optimized as a whole, defining the ideal performance required by the system considered as a whole and the requirements of its subsystems for optimal performances".

If components with optimal performances are not technologically suitable, a balanced choice between the available components can be performed. Specific direction of future development ad substitution plans of components can be produced to ensure the development of an equilibrate system and ensuring long-time development plans on the basis of the evolution of the components on the critical paths for the main technical functions of the system.

The preceding considerations an effective model of this design method can be defined. It introduces an effective improvement on the previously defined models maintaining the distinction in two different steps a preliminary top-down optimization, a successive bottom-up design and a final definition of direction for future improvement. The steps of this design methodology can reassume as follows:

1. top down design activity:

a. definition of the most ambitious possible objectives for the desired product;

b. complete identification of the physical laws at full system level for a preliminary theoretical optimization of the system at full scale; 
Fig. 6 Constructal design and system subdivision into modules, with identification of critical element and critical path

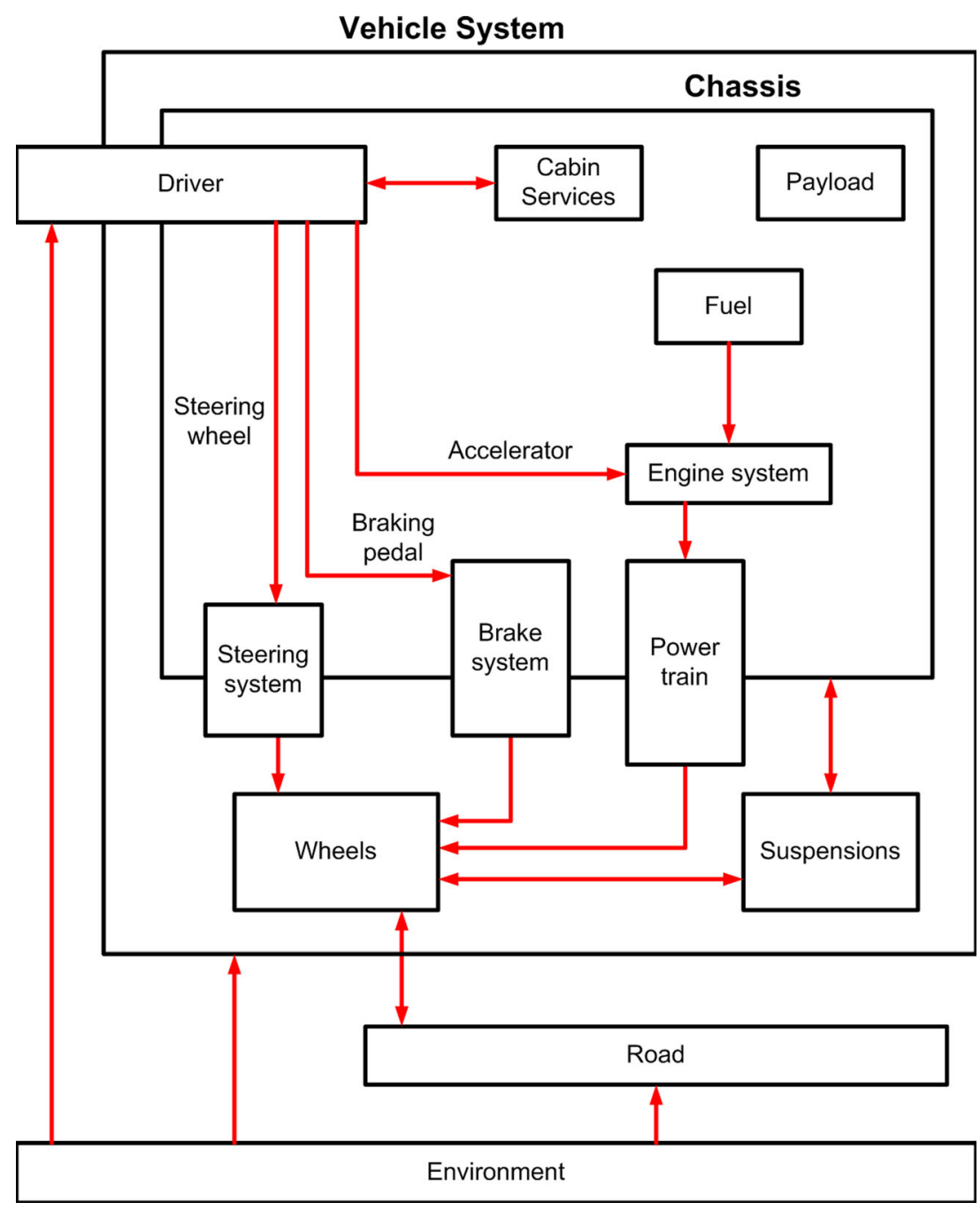

c. definition of an ideal system with ideal characteristics and performances,

d. definition of the internal functional modules (internal subsystem with a specific function) which must be connected in parallel and avoiding connection in series in any case that it can be possible, so to minimize mutual influences between the modules;

e. optimization of the internal functional modules for the desired to reach the ideal performances defined at system level;

f. identification of the sub-modules which constitute the functional modules connecting them in parallel and avoiding long connection in series, so to minimize mutual negative influences between the modules;

g. identification of the critical modules which has a larger effect on the performance of the functional module;

h. optimization of the critical modules defining their ideal performances to maximize the performances of the functional module; i. readiness against technology analysis to verify if the ideal sub-system could be feasible with disposable technology at industrial level;

j. if it could not be possible to realize the ideal critical subsystem it is then necessary to define technology ready solution, which ensures the acceptable performances;

k. repetition of the subsystem optimization steps ( $\mathrm{i}$ and $\mathrm{j}$ ) for any subsystem of the functional modules;

2. bottom-up design activity:

a. adoption of the critical subsystem as the best compromise found in preceding step;

b. identification of different possible alternatives of the functional modules using subsystems at technology readiness state

c. comparison between the different alternatives identifying the ones which ensures an acceptable compromises in terms of performances; 
Fig. 7 Example of schematic modular representation of a vehicle (some groups are represented on the separation line because the insist partially on the chassis and partially are outside the chassis)

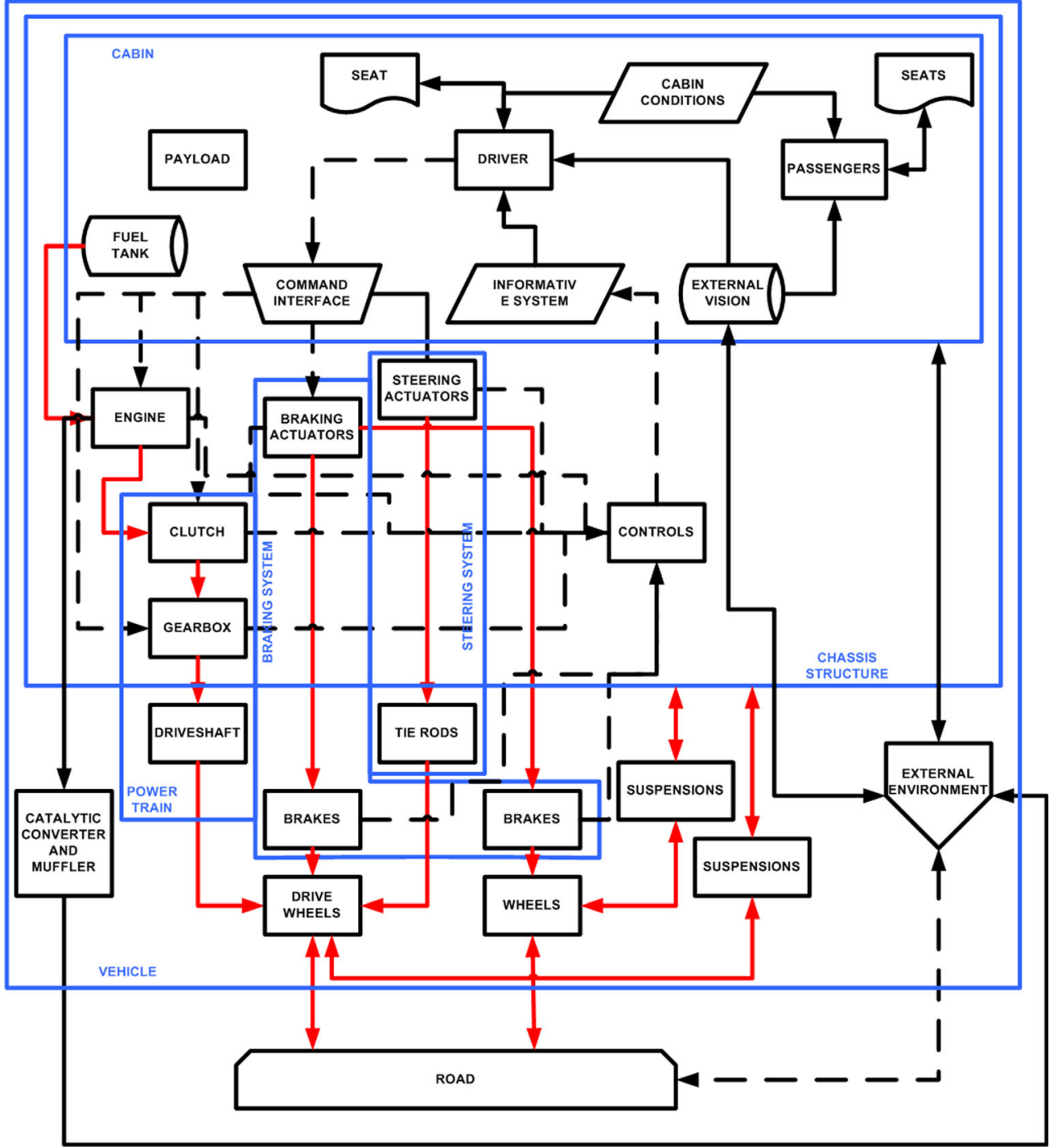

d. evaluations of the performances of the full product integrating the acceptable functional modules defined before;

e. identification of the better solution at the actual state of the art;

3. identification of future direction of improvement

a. assuming the difference between the ideal performances and the decrease produced by the application of real components it is possible to evaluate the future margins of improvements;

b. identification of the performance of the system assuming some ideal components and some ready at industrial level;

c. identification of the functional modules which needs to be updated to improve the performances significantly;

d. identification of the design path for better components identifying expected performances, which can be reached with their substitution.
The actual CDE model definition is still a provisional definition because of it take actually into account only the first law of thermodynamics and the constructal law. Even if it has produced very interesting results in terms of energetically self-sufficient airships by photovoltaic, it must be tested more in depth on different projects extending it on different industrial complex products.

In particular, it is also opportune to provide a better formulation, which does not consider only the energetic consumption of energy but also the quality of energy used for the specific needs. This integration will require taking into account for all the energy related processes also the second law of thermodynamics and the exergy evaluation.

\subsection{Future activities}

The actual CDE model definition is still a provisional definition because of it take actually into account only the first law of thermodynamics and the constructal law. Even if it has 
produced very interesting results in terms of energetically selfsufficient airships by photovoltaic, it must be necessarily tested more in depth on different projects extending it on different industrial complex products.

In particular, it is also opportune to provide a better formulation, which does not consider only the energetic consumption of energy but also the quality of energy used for the specific needs. This integration will require taking into account for all the energy related processes also the second law of thermodynamics and the exergy evaluation.

The first expected activity will be a detailed analysis of energy analysis methods on transport modes favouring a detailed analysis of methods proposed by bibliography in order to asses effective comparison modes between different transport system and to define validated criteria for the comparison of results against today automotive industry standards.

\section{Conclusions}

This paper has verified the existing correlation of the actual economic crisis with the serious level of technological maturity, which is affecting most industrial sectors. It has analysed the different design methods, which allows the design of complex industrial products and in particular of transport vehicles. For example, it has taken into consideration the case of automotive design. The development forced by MSD has produced a large increase in terms of mass of the vehicle, which contrasts with the minimum requirements for saving energy and reducing environmental impacts. It has also led to a strong standardization of vehicles and a competition on non-technical aspects, such as price, marketing, and service. Those elements are one of the main causes of technological maturity in most industrial sectors.

A possible solution could origin by Constructal law, and in particular, from the still embryonic Constructal Design for Efficiency method that has preliminary formulated by Trancossi and Dumas. It aims to produce an effective alternative to the Modular System Design, which maintains the same fundaments, but forces an evolution through an effective optimization at product level and component level. It is a derived formulation of the constructal law defined by Adrian Bejan, which aims to applicability at industrial and engineering level.

In particular, this paper gives a more accurate definition of the Constructal Design for Efficiency method, demonstrating how it can fits the operative principles of Modular System Design method and the concept of Product platform. It will have the merit of forcing to a continuous process, which could allow overcoming the actual dramatic maturity status of most industrial sectors.
It aims to define industrial ready product through two necessary passages: the preliminary design of an optimized ideal system, which is used a term of comparison to define the possible direction of evolution to optimize the product, and the subsequent optimization of the components considering them as inserted into the relative flux.

These processes are both a necessary part of an effective method, which aims to produce an effective technical evolution. They allow defining reasonable lines for future implementation and for future development and the direction of research, to respond to the technological needs, which are necessary to realize an effective and appreciable advancement.

It can be conclude that this method will also have the benefit of an effective restitution of the design process to the domain of physics, engineering and mathematics, favouring an effective industrial renaissance. It also aims to generate a future market, in which the substitution will be lead by an effective innovation, even breakthrough in comparison to the actual decline of human intelligence and creativity inside the industrial products.

Acknowledgments The present work was performed as part of Project MAAT | Multibody Advanced Airship for Transport | with ref. 285602, supported by European Union through the 7th Framework Programme.

A special thanks to Prof. Adrian Bejan for encouraging the activity in this paper, which aims to be a preliminary reference through future constructal optimization of transport vehicles.

Open Access This article is distributed under the terms of the Creative Commons Attribution License which permits any use, distribution, and reproduction in any medium, provided the original author(s) and the source are credited.

\section{References}

1. Urry J (2004) The 'system' of automobility. Theory Culture Soc 21(4/5):25-39

2. VV.AA., "Time, mobility and economic growth", HOP Associates, 2005

3. Weber M, Hoogma R, Lane B, Schot J (1999) Experimenting with sustainable transport innovations: a workbook for strategic niche management. Institute for Prospective Technological Studies, Seville

4. Kondratieff N (1922) The World economy and its conjunctures during and after the war. Regional Branch of the State Publishing House, Vologda

5. Kondratieff N (1984) The long wave cycle. Richardson \& Snyder, New York

6. Kondratieff N (2002) Long economic cycles and the theory of forecasting. Ekonomika, Moscow

7. Schumpeter J (1934) "The theory of economic development. Leipzig: Duncker and Humblot”, Cambridge: Harvard University Press, reprint. Oxford University Press, New York, p 1961

8. Schumpeter J (1939) Business cycles, vol 2 vols. McGraw-Hill, New York

9. Schumpeter J., "Capitalism, socialism and democracy", Harper and Brothers. 5th ed. London, 1976

10. Mensch G (1975) Stalemate in technology. Ballinger Publishing Company, Cambridge

11. Van Duijn J., "The long wave in economic life", Allen \& Unwin, 1983 
12. Avriel, M., Rijckaert, M.J. and Wilde, D.J. (eds.), "Optimization and design", Prentice-Hall, 1973

13. VV.AA., "Surviving the economic recession", Aviation today whitepaper, 2009

14. VV.AA., "2013 Global aerospace and defense industry outlook", Deloite, 2013

15. Maxton G, Wormald J (2004) Time for a model change: reengineering the global automotive industry. Cambridge University Press, Cambridge

16. Bechmann R., Scherk M., "Globalization in the automotive industry-impact and trends" in Globalization 2.0, Springer, 2010

17. Mamalis A. G., Spentzas K. G., Mamalis A. A., The impact of automotive industry and its supply chain to climate change: Some technoeconomic aspects, European Transport Research Review. 5:1-10, Springer, 2013, doi: 10.1007/s12544-013-0089-x

18. Ward D., Global Trends 2020 and Beyond: automobile use, environment and safety challenges, Paper presented on behalf of the FIA Foundation Report in Autoworld, Brussels 22nd June 2011

19. Turcksin L., Mairesse O., Macharis C., "Private household demand for vehicles on alternative fuels and drive trains: a review.", European Transport Research Review, 5 (3): 149-164, Springer, 2013, doi: 10.1007/s12544-013-0089-x

20. VV.AA., "Global-automotive-executive-survey-2013", KPMG, Amstelveen, Nederland, 2013

21. VV.AA., "The 2013 accenture consumer electronics products and services usage report", Accenture, Dublin, Ireland, 2013

22. Hyman R (2010) Social dialogue and industrial relations during the economic crisis : innovative practices or business as usual? International Labour Office Industrial and Employment Relations Department, Geneva

23. Sturgeon T (2003) "Modular production networks: a new American model of industrial organization", industrial and corporate change. Oxford J 11(3):451-496. doi:10.1093/icc/11.3.451

24. Avriel M (1973) Optimization and design. Prentice Hall, NJ

25. Erixon, O.G. and Ericsson, A., "Controlling design variants" Society of manufacturing engineers, 1999

26. Clark KB, Baldwin CY (2000) "Design rules. vol. 1: the power of modularity". MIT Press, Cambridge

27. Baldwin, C.Y., Clark, K.B., "The option value of modularity in design" Harvard business school, 2002

28. Papalambros P, Wilde D (2000) Principles of optimal design: modeling and computation, 2nd edn. Cambridge University Press, Cambridge

29. Steuer R (1986) Multiple criteria optimization: theory, computation and application. Wiley, New York

30. Cramer EJ, Dennis JE Jr, Frank PD, Lewis RM, Shubin GR (1994) Problem formulation for multidisciplinary optimization. SIAM J Optim 4(4):754-776

31. Raymer, D., "Aircraft design - A conceptual approach". American Institute of Aeronautics and Astronautics. ISBN 0-930403-51-7, 1992

32. Alexandrov N., Hussaini M., eds., "Multidisciplinary design optimization: State of the Art", Proceedings in Applied Mathematics Series; No. 80. Philadelphia, PA: Society for Industrial \& Applied Math, 1997. ISBN: 9780898713596

33. Vanderplaats G (2001) Numerical optimization techniques for engineering design, 3rd edn. Vanderplaats Research and Development Inc., Colorado Springs

34. Eppinger S (1991) Model-based approaches to managing concurrent engineering. J Eng Des 2:283-290

35. Browning T (2001) Applying the design structure matrix to system decomposition and integration problems: a review and new directions. IEEE Trans Eng Manag 48(3):292-306

36. Browning T (2002) "Process integration using the design structure matrix,". Syst Eng 5(3):180-193

37. Holland J (1992) Adaptation in natural and artificial systems, 2nd edn. MIT Press, Cambridge
38. Baldwin C., and Clark K. (2006) "Modularity in the design of complex engineering systems", in understanding complex systems, pp 175-205, Springer

39. Ulrich K (1995) The role of product architecture in the manufacturing firm. Res Policy 24(3):419-441. doi:10.1016/0048-7333(94)007753, 1995

40. Muffatto M (1999) Platform strategies in international new product development. Int J Opera Prod Manag 19(5/6):449-460. doi:10. 1108/01443579910260766

41. Brylawski M., "Uncommon knowledge: Automobile platform sharing's potential impact on advanced technologies", 1st international automotive conference. international society for the advancement of material and process engineering, society for the advancement of material and process engineering (SAMPE), 2010

42. Schlie E, Yip G (2004) Regional follows global: strategy mixes in the world automotive industry. Eur Manag J 18(4):343-354. doi:10. 1016/S0263-2373(00)00019-0

43. Wong JY (2008) Theory of ground vehicles, 4th edn. Wiley, New York

44. Sovran G, and Bohn M., "Formulae for the tractive energy requirements of vehicles driving the EPA schedules," SAE paper 810184, 1981

45. COM 494 of 2 December 1992: 'The future development of the common transport policy'

46. COM 370, 12/09/2001: 'European transport policy for 2010: time to decide'

47. VISION 2020, Report of group of personalities, January 2001

48. COM 370, 12/09/2001: The white paper

49. COM 2020 (2010), Europe 2020: a European strategy for smart, sustainable and inclusive growth

50. Bejan A., and Lorente S., "Constructal theory of generation of configuration in nature and engineering", J. Appl. Phys., 100, 2006, doi: $10.1063 / 1.2221896$

51. Bejan A, Lorente S (2010) The constructal law of design and evolution in nature. Philos Trans R Soc B 365:1335-1347

52. Bejan A, Lorente S (2011) The constructal law and the evolution of design in nature. Phys Life Rev 8:209-240

53. Bejan A (1997) Advanced engineering thermodynamics, 2nd edn. Wiley, New York

54. Reis AH (2006) Constructal theory: from engineering to physics, and how flow systems develop shape and structure. Appl Mech Rev 59: 269-281. doi:10.1115/1.2204075

55. Wang L (2011) Universality of design and its evolution. Phys Life Rev 8:257-258

56. Miguel AF (2010) Natural flow systems: acquiring their constructal morphology. Int J Des Nat Ecodyn 5:230-240

57. Bejan A, Lorente S (2008) Design with constructal theory. Wiley, Hoboken

58. Eslami M, Jafarpur K (2012) Optimal distribution of imperfection in conductive constructal designs of arbitrary configurations. J Appl Phys 112:104905

59. Trancossi, M., Dumas, A., and Madonia, M., "Optimization of airships with constructal design for efficiency method," SAE technical paper 2013-01-2168, 2013, doi:10.4271/2013-01-2168

60. Trancossi M., Dumas A.,Madonia M., "Constructal design for efficiency: the case of airship design", ASME International Mechanical Engineering Conference 2013, American Society of Mechanical Engineers, 2013

61. Dumas A, Madonia M, Trancossi M, Vucinic D (2013) Propulsion of photovoltaic cruiser-feeder airships dimensioning by constructal design for efficiency method. SAE Int J Aerosp 6(1):273-285. doi:10. 4271/2013-01-2303

62. Trancossi M., Madonia M., Dumas A., "Constructal design for efficiency: The case of an entropic wall with circulating water, ASME international mechanical engineering conference 2013, American society of mechanical engineers, 2013 